\title{
SECTION 2: THE RESULTS
}

\subsection{Distribution of Samples}

The sets of core samples were distributed to over 120 laboratories that had returned an original questionnaire seeking expressions of interest in participation. A reporting format for the results was also agreed and distributed to the laboratories at the same time. This is shown in Table 2.1. Laboratories were originally given $1 \mathrm{yr}$ (i.e., to August 2000) to complete the analyses and return the results, but this was later extended to December 2000. In this section, we briefly describe the laboratory characteristics and the overall response rate of the participating laboratories.

\section{Table 2.1 The agreed reporting format}

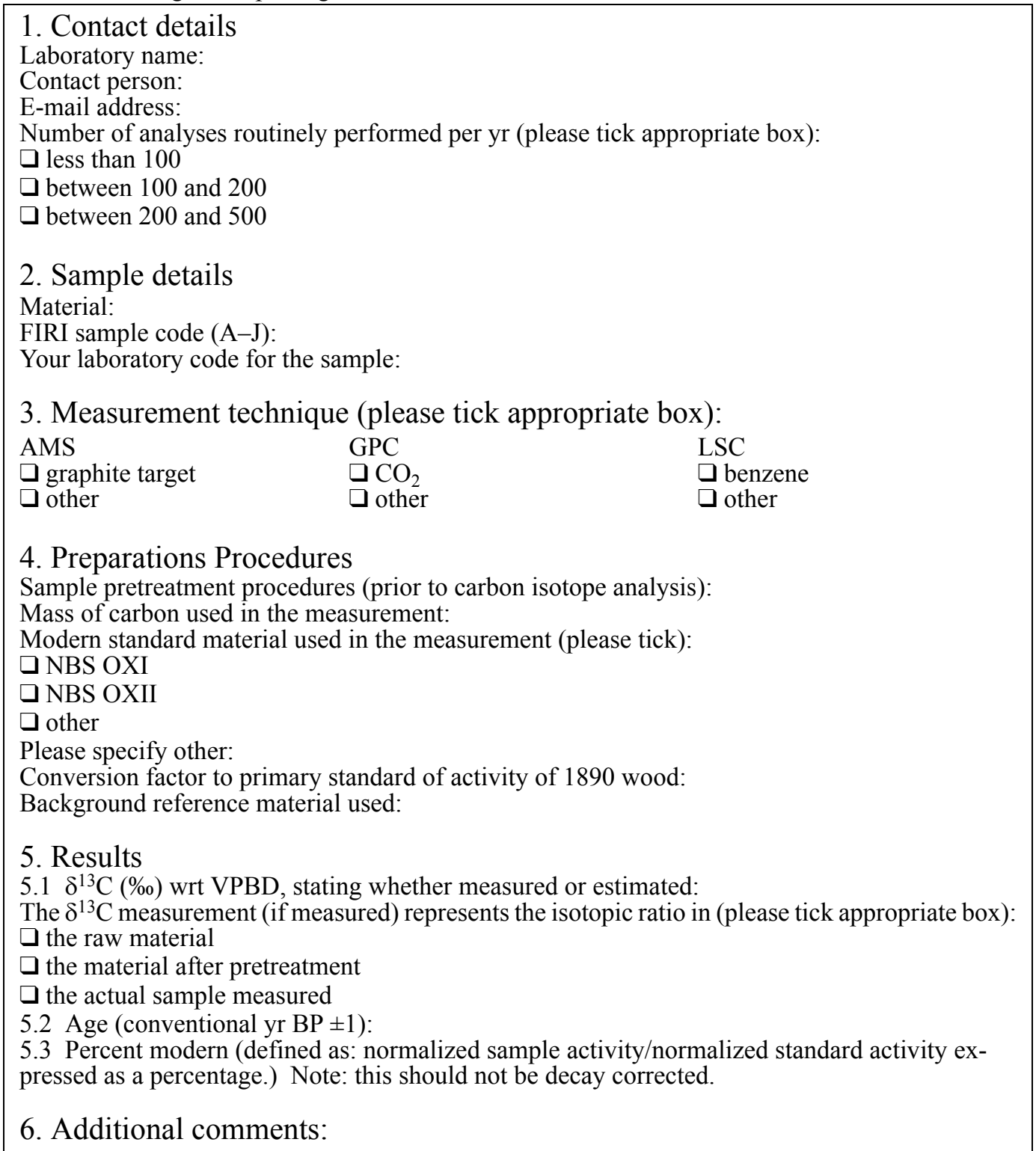




\subsection{THE BASIC LABORATORY DEMOGRAPHICS}

\subsubsection{Laboratory Completion Rate}

By the extended deadline of December 2000, sets of results from 85 laboratories had been received. The list of participating laboratories, as well as the technique used, are shown in Table 2.2. This represents a completion rate of $75 \%$, which is extremely successful and exceeds that recorded in the previous intercomparison (TIRI). The reported results are provided in Appendix 1.

Table 2.2 Participating laboratories

\begin{tabular}{lll}
\hline Laboratory name & Laboratory type & Country \\
\hline LATYR, La Plata & LSC & Argentina \\
Pabellón INGEIS & LSC & Argentina \\
CSIRO, Glen Osmond & Direct Absorption & Australia \\
ANTARES AMS Centre, ANSTO & AMS & Australia \\
Arsenal Research & LSC & Austria \\
VERA, Universität Wien & AMS & Austria \\
VRI, Institut für Radiumforschung und Kernphysik & GPC & Austria \\
IRPA, KIK & LSC & Belgium \\
IGSB, Minsk & LSC & Belarus \\
Environmental Isotope Lab, University of Waterloo & LSC & Canada \\
AECL, Chalk River & Direct Absorption & Canada \\
Geological Survey of Canada (GSC) & GPC & Canada \\
EHPL-Env, Ontario Hydro & Direct Absorption & Canada \\
IOEE Chinese Academy of Sciences & LSC & China \\
Ruđjer Bošković Institute & GPC & Croatia \\
Institut für Fysik, University of Aarhus & AMS & Denmark \\
Institute of Geology, Tallinn & LSC & Estonia \\
Geological Survey of Finland, Espoo & GPC & Finland \\
University of Helsinki & GPC & Finland \\
IPSN/LMRE, Orsay & LSC & France \\
HIGL, Paris-Sud University & AMS (GIF) & France \\
Tandetron-Gif & AMS & France \\
Université Claude Bernard, Lyon & LSC & France \\
Umweltforschungzentrum Leipzig-Halle & LSC & Germany \\
Leibniz, Universität Kiel & AMS & Germany \\
IUF, Universität Köln & GPC & Germany \\
UFZ-CER, PRG, Halle & LSC & Germany \\
Institut für Bodenkunde, Universitat Hamburg & LSC & Germany \\
Heidelberg University & GPC & Germany \\
DAI, Berlin & GPC & Germany \\
IGR, NLB, Hannover & GPC & Germany \\
Universität Erlangen, Nürnberg & AMS & Germany \\
LOIH, Institute of Physical Chemistry, Demokritos & LSC & Greece \\
LOA, Institute of Materials Science, Demokritos & GPC & Greece \\
Institute of Nuclear Research, HAS & GPC & Hungary \\
Physical Research Lab, Earth Sciences Div, & LSC & India \\
Ahmedabad & & \\
\hline
\end{tabular}


Table 2.2 Participating laboratories (Continued)

\begin{tabular}{|c|c|c|}
\hline Laboratory name & Laboratory type & Country \\
\hline $\begin{array}{l}\text { Physical Research Lab, Radiocarbon Dating Lab, } \\
\text { Ahmedabad }\end{array}$ & LSC & India \\
\hline Birbal Sahni Institute, Lucknow & LSC & India \\
\hline CRDIRT, JCPJ, Jakarta & LSC & Indonesia \\
\hline University College Dublin & LSC & Ireland \\
\hline Kimmel Center, Weizmann Institute & LSC & Israel \\
\hline RDL, University of Rome, La Sapienza & GPC and LSC & Italy \\
\hline Kyushu Environmental Evaluation Association & LSC & Japan \\
\hline Institute for Advanced Science, Osaka & LSC & Japan \\
\hline Palynosurvey Co & LSC & Japan \\
\hline CCR Nagoya University & AMS & Japan \\
\hline Gakushuin University, Tokyo & GPC & Japan \\
\hline Kyoto Sangyo University & GPC & Japan \\
\hline Seoul National University & AMS & Korea \\
\hline Institute of Geology, Vilnius & LSC & Lithuania \\
\hline RJ van de Graaff Lab, Utrecht & AMS & Netherlands \\
\hline Center for Isotope Research, Groningen & GPC/AMS & Netherlands \\
\hline Rafter Lab, Institute of Geological Sciences & AMS & New Zealand \\
\hline University of Waikato & LSC & New Zealand \\
\hline Radiological Dating Laboratory, Trondheim & GPC & Norway \\
\hline Silesian Technical University, Gliwice & GPC & Poland \\
\hline Archaeological and Ethnographical Museum, Łódź & LSC & Poland \\
\hline Instituto Technológico e Nuclear, Sacavém & LSC & Portugal \\
\hline Geological Institute, RAS & LSC & Russia \\
\hline Geographical Research, St. Petersburg State U. & LSC & Russia \\
\hline Institute of Geography, RAS & LSC & Russia \\
\hline Institute of Ecology and Evolution, RAS & LSC & Russia \\
\hline Institute of History of Material Culture, RAS & LSC & Russia \\
\hline Instituto de Química-Fisíca Rocasolano, Madrid & LSC & Spain \\
\hline University of Granada & LSC & Spain \\
\hline Facultad de Química, Universitat de Barcelona & LSC & Spain \\
\hline Tandem Lab, University of Uppsala & AMS & Sweden \\
\hline Universitat Bern & GPC & Switzerland \\
\hline ETH, Zurich & AMS & Switzerland \\
\hline Department of Geology, NTU & LSC & Taiwan \\
\hline Office of Atomic Energy for Peace & Direct Absorption & Thailand \\
\hline School of Geosciences, Queen's University, Belfast & LSC & UK \\
\hline Research Lab for Archaeology, Oxford & AMS & UK \\
\hline SUERC, East Kilbride & LSC and AMS (AA) & UK \\
\hline NERC Radiocarbon Lab & LSC/AMS (AA) & UK \\
\hline Lab of Radioecology, KIEV & LSC & Ukraine \\
\hline USGS, Reston & AMS (LLNL) & USA \\
\hline Beta Analytic Inc, Florida & LSC and AMS (LLNL) & USA \\
\hline NSF, Arizona & AMS & USA \\
\hline Geochron Labs, Cambridge, Massachusetts & LSC/GPC/AMS (LLNL) & USA \\
\hline
\end{tabular}


Table 2.2 Participating laboratories (Continued)

\begin{tabular}{lll}
\hline Laboratory name & Laboratory type & Country \\
\hline CAMS/LLNL & AMS & USA \\
NOSAMS WHOI & AMS & USA \\
INSTAAR, University of Colorado at Boulder & AMS (WHOI) & USA \\
University of California, Riverside & AMS (LLNL) & USA \\
ISGS, Illinois & LSC & USA \\
\hline
\end{tabular}

In summary, the broad geographical distribution for the laboratories is shown in Table 2.3 below.

Table 2.3 Geographical distribution

\begin{tabular}{ll}
\hline Broad geographical description & Number of laboratories \\
\hline Europe (EU) & 35 \\
Europe (non EU) & 17 \\
North America and Canada & 13 \\
South America & 2 \\
Asia and the Far East & 13 \\
Australia and New Zealand & 4 \\
\hline
\end{tabular}

The summary of the numbers of laboratories using the different techniques is shown in Table 2.4.

Table 2.4 Laboratory type

\begin{tabular}{ll}
\hline Laboratory type & Number \\
\hline LSC & 44 \\
GPC & 19 \\
AMS & 17 \\
Target feeder for AMS & 8 \\
Direct absorption and LSC & 4 \\
\hline
\end{tabular}

Thus, almost half of the participating laboratories use liquid scintillation. Virtually all operational AMS facilities participated.

Although we have a total of 85 identified participating laboratories, several laboratories operate different independent measurement systems; thus, the total number of submitted sets of results (92) exceeded this figure. Eight laboratories submitted results for AMS, through target preparation and then measurement in a remote facility. In 2 such cases, these samples were measured at the NSF Arizona facility; in 4, the analyses were performed at CAMS/LLNL; while 1 was measured in Tandetron-Gif and 1 measured at NOSAMS WHOI. These sets of results were treated as independent. Some laboratories also submitted more than 1 set of results for a given sample.

\subsection{MODERN STANDARD AND BACKGROUND MATERIAL}

Other potentially useful general information, which was collected at the time of the submission of results, concerned the background and modern standard materials used by the laboratories, the method of pretreatment applied (if any), the number of routine analyses performed per yr, and information about the measurement of $\delta^{13} \mathrm{C}$. Not all laboratories provided all of this ancillary 
information. The background and modern standard materials used are surprisingly diverse, but have been broadly categorized to allow a simple summary shown in Tables 2.5 and 2.6 below.

Table 2.5 Classifications used for background and modern standard

\begin{tabular}{ll}
\hline a) Background & \\
\hline Original description & Coding for analysis \\
\hline Anthracite & Anthracite (Anth) \\
Benzene & Benzene (Benz) \\
Calcite & Calcite (calc) \\
Charcoal & Charcoal (char) \\
Bituminous coal & Coal (coal) \\
Graphite & Graphite (graph) \\
Doublespar/IAEA C1 & Marble \\
IAEA C4/wood/limestone & Other \\
& \\
b) Modern standard & \\
\hline Original description & Coding for analysis \\
\hline ANU sucrose & ANU sucrose (ASUC) \\
Benzene & Benzene (Benz) \\
NIST OxI & NBS1 \\
NIST OxII & NBS2 \\
GIN/HD-95,C-3 & Other \\
NIST 1/II & NBS12 \\
\hline
\end{tabular}

Table 2.6 Numbers of laboratories using the identified background and modern standard materials a) Background material

\begin{tabular}{lc}
\hline Classification of material & Number of laboratories using this material \\
\hline Anthracite & 12 \\
Benzene & 17 \\
Calcite & 3 \\
Coal & 4 \\
Graphite & 3 \\
Marble & 25 \\
Other & 27
\end{tabular}

b) Modern standard materials used

\begin{tabular}{lc}
\hline Analysis classification & Number of laboratories using this material \\
\hline ANU sucrose & 9 \\
Benzene & 5 \\
NBS1 & 30 \\
NBS2 & 29 \\
NBS12 & 9 \\
other & 5 \\
\hline
\end{tabular}

It is clear that there is a wide diversity of background materials, but marble and benzene are common and popular choices. 
We can see that the NIST Oxalic acids predominate, but that there are still a few laboratories (19) that do not make use of these materials. In addition, we considered whether the distribution of materials was associated with the different measurement techniques.

Table 2.7 Numbers of laboratories of each type by background and standard material used

a) Background material used

\begin{tabular}{lccllllll}
\hline & \multicolumn{8}{c}{ Background material } \\
\cline { 2 - 9 } Laboratory type & Anth & benz & calc & coal & graph & Marble & other & All \\
\hline AMS & 3 & 0 & 2 & 0 & 2 & 15 & 8 & $\mathbf{3 0}$ \\
GPC & 6 & 0 & 0 & 3 & 1 & 4 & 3 & $\mathbf{1 7}$ \\
LSC & 3 & 17 & 1 & 1 & 0 & 6 & 6 & $\mathbf{3 4}$ \\
All & 12 & 17 & 3 & 4 & 3 & 25 & 17 & $\mathbf{8 1}$
\end{tabular}

b) Modern standard material used

\begin{tabular}{llllllll}
\hline & \multicolumn{7}{c}{ Standard material } \\
\cline { 2 - 8 } Laboratory type & ASUC & Benz & NBS1 & NBS12 & NBS2 & other & All \\
\hline AMS & 1 & 0 & 16 & 9 & 5 & 1 & $\mathbf{3 2}$ \\
GPC & 1 & 0 & 7 & 0 & 7 & 3 & $\mathbf{1 8}$ \\
LSC & 7 & 5 & 7 & 0 & 17 & 1 & $\mathbf{3 7}$ \\
All & 9 & 5 & 30 & 9 & 29 & 5 & $\mathbf{8 7}$
\end{tabular}

c) Modern standard by background material used

\begin{tabular}{lccllllrr}
\hline & \multicolumn{8}{c}{ Background } \\
\cline { 2 - 9 } Standard & Anth & benz & calc & coal & graph & Marble & other & All \\
\hline ASUC & 1 & 1 & 1 & 1 & 0 & 3 & 2 & $\mathbf{9}$ \\
Benz & 0 & 4 & 0 & 0 & 0 & 0 & 0 & $\mathbf{4}$ \\
NBS1 & 4 & 2 & 1 & 0 & 0 & 10 & 11 & $\mathbf{2 8}$ \\
NBS12 & 0 & 0 & 1 & 0 & 0 & 6 & 0 & $\mathbf{7}$ \\
NBS2 & 7 & 8 & 0 & 2 & 2 & 5 & 3 & $\mathbf{2 7}$ \\
Other & 0 & 1 & 0 & 1 & 1 & 1 & 1 & $\mathbf{5}$ \\
All & 12 & 16 & 3 & 4 & 3 & 25 & 17 & $\mathbf{8 0}$ \\
\hline
\end{tabular}

There appears to be no strong evidence of an association between the background and modern standard material used with the measurement technique. It is clear that there are a number of commonly used background materials including, anthracite, benzene (only LSC), and marble (predominantly AMS). The NIST modern standards are widely used, but some laboratories do not make use of these materials and rely on ANU sucrose, benzene, and other materials.

\subsection{HOW BUSY ARE THE LABORATORIES?}

When submitting their results, laboratories were also asked to provide an approximate figure of the number of analyses they performed per yr. It was thought that this information might be helpful in understanding any outlier distribution and also in explaining deviations from sample consensus values and variation. A brief summary of the findings is presented in the following. 


\subsubsection{Number of Analyses Carried Out Per Year}

The are 4 levels for the "number of analyses performed":

- 1 indicates $<100$ analyses done per yr by that laboratory;

- 2 indicates $100-200$

- 3 indicates $200-500$;

- 4 indicates $>500$.

First, we consider the association between laboratory type and the number of analyses performed per yr.

Table 2.8 Numbers of laboratories in each Technique/Nr-of-analyses-per-year category

\begin{tabular}{lcrcr}
\hline & \multicolumn{4}{c}{ Nr of analyses per yr } \\
\cline { 2 - 5 } Laboratory type & \multicolumn{1}{c}{2} & 3 & 4 \\
\hline AMS & 0 & 1 & 5 & 17 \\
GPC & 1 & 8 & 3 & 4 \\
LSC & 14 & 17 & 4 & 6 \\
All & 15 & 26 & 12 & 27 \\
\hline
\end{tabular}

As expected, the AMS laboratories predominantly do over 500 analyses per $\mathrm{yr}(17 / 23=74 \%)$, while radiometric laboratories predominantly do fewer than 200 analyses per $\mathrm{yr}([1+8+14+17] /(16+41)$ $=70 \%)$, particularly LSC labs $([14+17] / 41=76 \%)$

Table 2.9 Numbers of results returned in FIRI by laboratories in each technique categorized by Number-of-analyses-per-yr category

\begin{tabular}{lrrrrr}
\hline & \multicolumn{5}{c}{ Number of analyses per yr } \\
\cline { 2 - 6 } Laboratory type & \multicolumn{1}{c}{1} & \multicolumn{1}{c}{3} & \multicolumn{1}{c}{ 3 } & All \\
\hline AMS & 0 & 10 & 52 & 298 & $\mathbf{3 6 0}$ \\
GPC & 9 & 92 & 38 & 41 & $\mathbf{1 8 0}$ \\
LSC & 113 & 185 & 33 & 64 & $\mathbf{3 9 5}$ \\
All & 122 & 287 & 123 & 403 & $\mathbf{9 3 5}$ \\
\hline
\end{tabular}

We note that the number of results submitted to FIRI per laboratory tends to increase as the number of analyses per yr carried out increases from an average of $8(122 / 15)$ per laboratory for those doing less than 100 analyses per yr to 15 (403/27) for those doing over 500 per yr.

\subsection{Conclusions}

These demographic summaries indicate that there is a substantial diversity in the background and the modern standard material used by the laboratories. In particular, a number of laboratories do not routinely use the NIST primary standards. The background materials used are predominantly inorganic, which may prove a factor in the analysis of the Kauri wood samples (A and B). There is a substantial variation among laboratories in the number of analyses per yr which are performed. As would be expected, the AMS laboratories are typically performing substantially more analyses than the radiometric laboratories. 